\title{
MUSIK TURUNANI SEBAGAI SUMBER INSPIRASI PENCIPTAAN MUSIK ETNIS DENGAN JUDUL MO'ELA
}

\author{
Rangga Setiawan Monoarfa \\ Program Magister Tata Kelola Seni ISI Yogyakarta \\ anggamonoarfa120897@gmail.com
}

\begin{abstract}
Abstrak
Komposisi Mo'ela merupakan suatu bentuk karya musik etnis yang lahir dari tradisi lisan dan pola ritme rebana masyarakat Gorontalo. Kisah hidup Nabi Ayyub AS oleh masyarakat Gorontalo diterjemahkan ke dalam pola-pola ritmis rebana yang sampai sekarang masih dipakai khususnya dalam kesenian Turunani. Kisah Nabi Ayyub AS dengan pola-pola ritme rebana tesebut kemudian ditransformasikan ke dalam sebuah karya musik etnis. Penciptaan sebuah karya komposisi musik tentu memerlukan metode sabagai landasan guna mewujudkan sebuah bentuk karya seni yang ideal. Pada kesempatan ini metode yang digunakan mengacu pada teori Alma M. Hawkins. Teori ini sering digunakan dalam komposisi karya-karya seni sebelumnya, yang menjadi kitab suci di Jurusan Seni Tari. Namun demikian teori ini bisa diaplikasikan dalam penciptaan musik etnis. Adapun teori penciptaan ini meliputi ekplorasi, improvisasi dan pembantukan atau komposisi. Penyajian komposisi Mo'ela merupakan sebuah campuran antara instrumen etnis, barat dan olahan vokal. Selain itu juga diadopsi beberapa pola atau motif tabuhan dari rebana Gorontalo yang kemudian dikembangkan dengan teknik-teknik penggarapan musik. Bentuk penyajian yang ada dalam karya komposisi musik etnis Mo'ela mengacu pada kisah hidup Nabi Ayyub AS dan pola ritme rebana Gorontalo, secara garis besar terdapat tiga bagian suasana peristiwa dalam karya.
\end{abstract}

Kata Kunci: Mo'ela, Turunani, Gorontalo

\begin{abstract}
The composition of Mo'ela is a form of ethnic music that was born from oral traditions and the tambourine rhythm patterns of the Gorontalo people. The life story of the Prophet Ayyub AS by the Gorontalo people was translated into rhythmic tambourine patterns which are still used today, especially in the art of Greek. The story of the US Ayyub with tambourine rhythm patterns was then transformed into a work of ethnic music. The creation of a musical composition work certainly requires a method as a basis for realizing an ideal form of art. On this occasion the method used refers to the theory of Alma M. Hawkins. This theory is often used in the composition of previous works of art, which became the holy book in the Dance Department. However, this theory can be applied in the creation of ethnic music. The theory of creation includes exploration, improvisation and co-administration or composition. Presentation of the composition of Mo'ela is a mixture of ethnic, western and vocal preparations. Besides that, some wasps patterns or motifs from the tambourine of Gorontalo were also adopted, which were then developed with techniques for making music. The form of presentation in Mo'ela's ethnic music composition refers to the life story of the Prophet Ayyub AS and Gorontalo tambourine rhythm patterns, in broad outline there are three parts to the atmosphere of events in the work.
\end{abstract}

Keywords: Mo'ela, Turunani, Gorontalo 


\section{A. Pendahuluan}

Musik merupakan cabang seni yang membahas dan menetapkan berbagai suara ke dalam pola-pola yang dapat dimengerti dan dapat dipahami manusia. Oleh karena itu, musik dapat dimengerti sebagai hasil olah pikir maupun olah rasa oleh manusia untuk manusia. Selain itu, musik sendiri merupakan bentuk seni yang melibatkan penggunaan bunyi secara terorganisir melalui kontinum waktu tertentu. Oleh karena itu musik tidak dapat dilepaskan dari aspek kompositoris yang dalam hal ini ialah durasi maupun aspek sejarah yang meliputi periodesasi waktu tertentu. Setiap musik memiliki karakteristiknya masing-masing, dimana kondisi sosio-kultural dari peradaban tertentu turut andil dalam diversitas musik yang ada selama ini.

Filsuf Yunani yang bernama Aristoteles, menyatakan bahwa musik adalah curahan kekuatan tenaga dan kekuatan tenaga penggambaran (visualisasi) yang berasal dari gerak rasa dalam suatu rentetan suara (melodi) yang berirama. Lewat berbagai definisi musik di atas semakin mengafirmasikan bahwa terjadinya sebuah musik merupakan suatu konsekuensi dari campur tangan manusia dalam mengolah bunyi yang didapat lewat panca inderanya. Selain itu kesan yang didapat tersebut pada akhirnya diaktualisaksikan lewat dimensi bunyi yang telah diorganisir sebelumnya. Oleh karena itu, bunyi dedaunan yang ditiup angin ataupun suara kendaraan seperti mobil dan motor belum dapat disebut musik tanpa campur tangan kreativitas maupun olahan manusia. Selain pengolahan terhadap bunyi sebagai materi musik, elemen waktu (terepresentasikan lewat durasi) sekali lagi menjadi elemen penting dalam terjadinya sebuah karya musik. Elemen waktu yang dianggap penting dalam hal ini perjalanan olah rasa dan proses kreativitas dari awal gagasan hingga pengolahan menuju kesatu karya membutuhkan beberapa tahap. Tahaptahap itulah yang dijadikan elemen waktu. Begitu pula menentukan suatu karya ataupun judul memerlukan beberapa tahapan yang harus dilalui. Demikian halnya ketika seseorang ingin menentukan judul tersebut harus melalui beberapa tahap. Langkah tersebut juga dilalui penulis dalam menentukan judul komposisi yang berjudul Mo'ela.

Pemilihan Mo'ela sebagai judul karya penciptaan musik etnis yang diangkat disesuaikan dengan konsepsi serta tujuan utama dalam penggarapan komposisi karya ini. Karya musik ini diberi judul Mo'ela, dimana kata Mo'ela diambil dari bahasa Gorontalo yang artinya "Mengenang". Pemilihan Mo'ela sebagai judul karya musik ini 
sesuai dengan konteks yang dipilih yaitu dengan mengambil kisah hidup Nabi Ayyub AS yang sangat sabar dalam menghadapi ujian dari Allah SWT. Kisah hidup Nabi Ayyub AS tersebut oleh masyarakat Gorontalo diterjemahkan ke dalam pola-pola ritmis rebana yang sampai sekarang masih dipakai khususnya dalam kesenian turunani.

Turunani merupakan tradisi peninggalan leluhur yang berasal dari Gorontalo. Sejak dahulu berbagai jenis sastra lisan Gorontalo telah ada, namun sedikit sekali usaha yang dilakukan untuk menggali dan menyusun sehingga menjadi satu dokumentasi yang lengkap. Hal ini merupakan suatu gejala yang berdampak secara meluas dalam menghadapi berbagai warisan budaya masa lampau. Selain itu, kenyataan pula bahwa yang masih dapat menceritakan hasil sastra lisan itu hanya orang yang sudah lanjut usia dan dalam jumlah yang sedikit.

Tradisi lisan ini digunakan masyarakat dalam berbagai kenduri, misalnya dalam upacara adat gunting rambut, upacara adat pernikahan, upacara adat sunatan dan upacara adat pembeatan. Pada pelaksanaan kenduri ini, tuan rumah yang membuat kenduri menyediakan tempat bagi yang ber-turunani untuk melakukan lafal turunani dengan diiringi rebana. Tradisi ini disebut turunani, ada juga yang menyebutnya sulunani. Sulunani ini merupakan sebutan dari salah seorang budayawan yang bernama Yamin Husain (63 tahun), sulunani diartikan dengan suruh nyanyi. Sebutan ini dipengaruhi bahasa Indonesia, sehingga sebutan sulunani sering juga disebut surunani. Berdasarkan uraianuraian yang telah dijelaskan, sulunani atau surunani atau turunani dapat dibatasi sebagai berikut, yaitu tradisi lisan yang diujarkan dalam bahasa Arab dengan intonasi lagu tertentu dan diiringi pukulan rebana yang dilaksanakan dalam konteks kenduri tertentu.

Dalam kesenian turunani terdapat sastra lisan yang membahas kisah Nabi Ayyub AS. Beliau memiliki harta yang banyak dengan bermacam jenisnya, seperti hewan ternak, budak, dan tanah. Beliau juga memiliki istri yang saleh dan keturunan yang baik. Sebagaimana dalam hadits yang diriwayatkan oleh Tirmidzi dan Ibnu Majah, dihasanahkan oleh Syaikh Al Albani dalam Shahihul Jami' nomor 2110 bahwa Allah SWT ingin mengujinya, dan Allah apabila mencintai suatu kaum, maka Dia menguji mereka, barang siapa yang ridha dengan ujian tersebut, maka dia mendapatkan keridhaan-Nya dan barang siapa yang marah terhadap ujian tersebut, maka dia mendapatkan kemurkaanNya. Ayyub adalah orang yang sabar dalam menghadapi ujian tersebut, 
hartanya yang banyak habis, anak-anaknya meninggal dunia, semua ternaknya binasa, dan Nabi Ayyub AS sendiri menderita penyakit yang sangat berat, tidak ada satu pun dari anggota badan Nabi Ayyub AS yang terbebas dari penyakit, hanya hati dan lisannya yang beliau gunakan untuk berdzikir kepada Allah Subhanahu Wa Ta'ala.

Pada saat beliau terserang penyakit, beliau pun membacakan La Ilaha Illallah dan tangan beliau diusapkan tepat dibagian dada beliau sebanyak tiga, lima dan tujuh. Dibacanya kalimat La Ilaha Illallah dan diusapkan tangannya tepat di bagian dada beliau sebanyak tiga, lima, dan tujuh oleh Nabi Ayyub AS. Masyarakat Gorontalo mengangkat tiga, lima, dan tujuh itu menjadi pola ritmis rebana Gorontalo yang dipakai hingga saat ini. Nama ritmis itu tidak diubah namanya dan tetap memakai nama itu, yang biasa disebut oleh masyarakat Gorontalo dengan pukulan tiga, lima, dan tujuh. Pukulan tiga, lima, dan tujuh selalu ada dalam turunani.

Pola turunani menggunakan satu jenis instrumen ritmis saja yaitu rebana. Hal ini menjadi sumber inspirasi sebagai ide garapan komposisi musik Mo'ela. Dalam hal ini bagaimana pengolahan ritmis rebana menjadi sebuah komposisi musik. Untuk mendukung suasana pada karya ini maka ditambahkan instrumen-instrumen barat seperti bass, bongo, gambus oud, dan ditambahkan juga instrumen tradisi yang berasal dari Gorontalo seperti polo-palo, rebana Gorontalo, dan marwas. Sehingga menimbulkan kesan melayu dalam garapan musik itu sendiri.

Berdasarkan latar belakang di atas, maka mendapatkan ide dan gagasan untuk dituangkan ke dalam komposisi musik etnis. Gagasan untuk menggabungkan beragam idiom tersebut melalui proses musikal yakni dengan cara eksplorasi, improvisasi dan pembentukan dengan beberapa instrumen yaitu: biola, flute, xelophone, cello, syntizer, gambus oud, bedug, kick drum, rebana, simbal, bongo, dan bass elektrik. Dari beberapa konsep gabungan itu akhirnya mendapatkan satu rumusan ide penciptaan yakni bagaimana mewujudkan kisah Nabi Ayyub AS semasa hidupnya yang terdapat pada sastra lisan daerah Gorontalo dalam bentuk musik etnis yang berjudul Mo'ela.

Karya Mo'ela merupakan musik yang berbentuk vokal instrumental, di mana karya ini merupakan perpaduan antara beberapa instrumen barat dengan instrumen timur yang di dalamya ada beberapa isntrumen musik khas dari Gorontalo. Karya musik ini pun menggunakan teori Alma M. Hawkins, dengan menggunakan metode penciptaan eksplorasi, improvisasi, dan komposisi. Penciptaan karya ini juga dipadukan 
berdasarkan pengalaman maupun teori atau cara-cara yang didapat selama menempuh pendidikan.

\section{B. Metode Penelitian Penciptaan}

Pembuatan karya atau komposisi memiliki beberapa tahap sebelum menjadi karya yang utuh.

\section{...Menggarap suatu komposisi berarti memikirkan tentang materi. Kita harus memikirkan tentang proses bagaimana suatu informasi dari manusia akan disampaikan kepada manusia lain. Supaya suatu karya musik masa kini akan memenuhi tuntutan ini, maka materi musik harus diperhatikan semua konsekuensi dilihat dari segi ekspresinya".}

Karya Mo'ela menggunakan metode penciptaan eksplorasi, improvisasi, dan komposisi, seperti yang terdapat pada buku Alma M.Hawkins, Creating Through Dance. Terj.Y. Sumandiyo Hadi "Mencipta Lewat Tari" (Yogyakarta: Institut Seni Indonesia Yogyakarta, 1990). Ketiga elemen tersebut dijadikan acuan metode bagi penulis dalam berkomposisi. Walaupun yang dijadikan acuan berkarya adalah referensi dari tari, namun bagi penulis tahap eksplorasi, improvisasi dan komposisi tersebut juga ada di dalam proses karya penciptaan musik etnis.
Ada beberapa tahap yang dilalui pengkarya sebelum komposisi musik menjadi karya maksimal, proses-proses yang dilalui adalah sebagai berikut.

a. Eksplorasi

Alma M. Hawkins memaparkan bahwa tahapan ini termasuk berpikir, berimaginasi, merasakan, dan merespon objek yang dijadikan sumber penciptaan. Eksplorasi merupakan bentuk imajinasi dari pengkarya terhadap karya. Selain itu pada eksplorasi penulis memikirkan penggunaan instrumen dan mencocokkan dengan karakter musik yang dipilih sebagai bentuk penyajian. Eksplorasi dalam hal ini berupa pengamatan secara langsung dan tidak langsung terhadap kesenian turunani yang sedemikian rupa menjadi alasan sehingga terbentuk karya ini. Pengamatan langsung dalam hal ini dimaksudkan yakni turut aktif berperan serta ke dalam sebuah kegiatan kesenian turunani, sedangkan yang tidak langsung berupa melakukan dialog tanya jawab antara penulis dan narasumber dan menonton kegiatan kesenian turunani. Semuanya dilakukan dengan tujuan agar dapat mengetahui latar belakang secara utuh dari kesenian turunani yang mana nantinya akan diangkat sebagai bahan komposisi musik.

Pengamatan terhadap kajian sumber juga dalam hal ini juga tidak kalah penting 
khususnya yang mengacu pada teori-teori komposisi, serta pencarian yang liar terhadap sumber bunyi atau dalam hal ini karakterkarakter bunyi instrumen yang nantinya akan dimasukkan ataupun digunakan dalam karya ini.

b. Improvisasi

Improvisasi memberikan kesempatan yang lebih besar bagi imajinasi, seleksi dan mencipta dari pada eksplorasi. Proses ini merupakan proses pemilihan dan merangkai beberapa motif untuk dijadikan sebuah bagian dalam komposisi, proses ini terjadi setelah melalui proses eksplorasi. Pencarian tema dan variasi dalam komposisi biasanya didapat ketika musik sudah mulai terbentuk disertai dengan beberapa elemen penting yang dikaitkan pada sumber yang dipilih. Pada tahap improvisasi ini dilakukan eksperimen terhadap instrumen yang dipergunakan seperti mengolah nada, harmoni, dan ritme. Selain itu juga penulis mulai mencoba menuangkan materi yang sebelumnya telah diamati menjadi sebuah komposisi musik etnis. Aktivitas kompositoris sudah mulai dilakukan demi tersusunnya sebuah komposisi musik etnis yang estetis mulai dari melakukan proses imitasi kedalam sebuah instrumen, pelebaran ritme, penyempitan interval nada sampai kemudian memainkannya dalam sebuah instrumen agar dapat memilah bunyi yang harmonis dan yang tidak harmonis.

c. Komposisi

Tujuan akhir dari pengalaman yang diarahkan sendiri dalam mencipta tari. Proses ini disebut komposisi, atau forming (membentuk). Kebutuhan membuat komposisi tumbuh dari hasrat manusia untuk memberi bentuk terhadap sesuatu yang ia temukan. Dalam pembentukan karya ini menggunakan idiom musik etnis timur (Melayu) yang memberikan keselarasan dalam karya ini. Instrumen musik barat juga digunakan dalam karya ini guna memberikan kesan yang baru saat berkolaborasi dengan instrumen timur. Dalam karya Mo'ela menggunakan tangga nada diatonis agar tidak menghilangkan karakter musik Barat, dan sekaligus pengaplikasian teori-teori musik barat yang diharmonisasikan kepada instrumen Timur agar menjadi satu kesatuan dalam sebuah komposisi karya musik etnis.

\section{Hasil dan Pembahasan}

Bentuk dalam Kamus Besar Bahasa Indonesia memiliki beberapa arti yaitu gambaran, rupa, wujud, sistem, dan susunan. Karl Edmund Prier SJ dalam bukunya yang berjudul Ilmu Bentuk Musik memaparkan pengertian bentuk musik (form): 
"suatu gagasan / ide yang nampak dalam pengolahan / susunan semua unsur musik dalam sebuah komposisi (melodi, irama, harmoni, dan dinamika). Ide ini mempersatukan nada-nada musik serta terutama bagianbagian komposisi yang dibunyikan satu per satu sebagai kerangka. Bentuk musik dapat dilihat juga secara praktis: sebagai 'wadah' yang 'diisi' oleh seorang komponis dan diolah sedemikian hingga menjadi musik yang hidup."

Karya Mo'ela merupakan musik yang berbentuk vokal instrumental, di mana karya ini merupakan perpaduan antara beberapa instrumen barat dengan instrumen timur yang di dalamya ada beberapa isntrumen musik khas dari Gorontalo. Karya musik Mo'ela dibagi mejadi tiga bagian yaitu, bagian awal (I), bagian tengah (II), bagian akhir (III). Ulasan lebih lanjut dari masing-masing bagian akan dijabarkan sebagai berikut.

\section{Bagian I}

Pada bagian pertama, berisi cerita atau menceritakan sosok Nabi Ayyub AS yang memiliki harta yang banyak dengan bermacam jenisnya, seperti: hewan ternak, budak, dan tanah. Ia juga memiliki istri yang saleh dan keturunan yang baik. Namun dengan banyaknya harta yang dimiliki Nabi Ayyub AS tidak pernah merasa sombong dan angkuh. Kedermawanan dan kemewahan Nabi Ayyub AS menjadi topik utama pada bagian ini.

\section{a. Kedermawanan}

Sikap kedermawanan beliau ditandai oleh instrumen cello, keyboard, dan bass elektrik yang memainkan satu akor saja yaitu A minor, penahanan disatu akor dirasa tepat untuk menggambarkan sikap kedermawanan. Instrumen oud dan flute berimprovisasi bersamaan dengan penahanan akor oleh instrumen cello, keyboard, dan bass elektrik. Improvisasi yang dimainkan merupakan respon dari penahanan satu akor tersebut. Pemilihan instrument gambus oud dan flute diharapkan dapat mewakili idiom musik Timur Tengah dengan mengimitasi pola pemainan ney ke dalam instrumen flute.
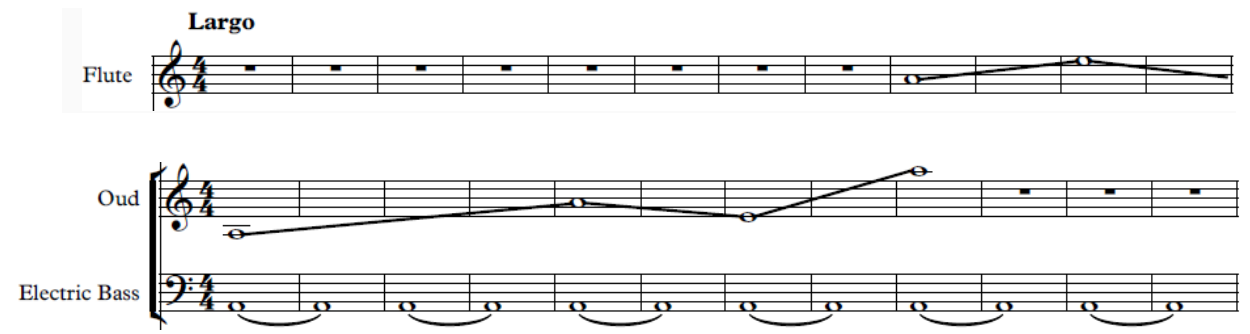

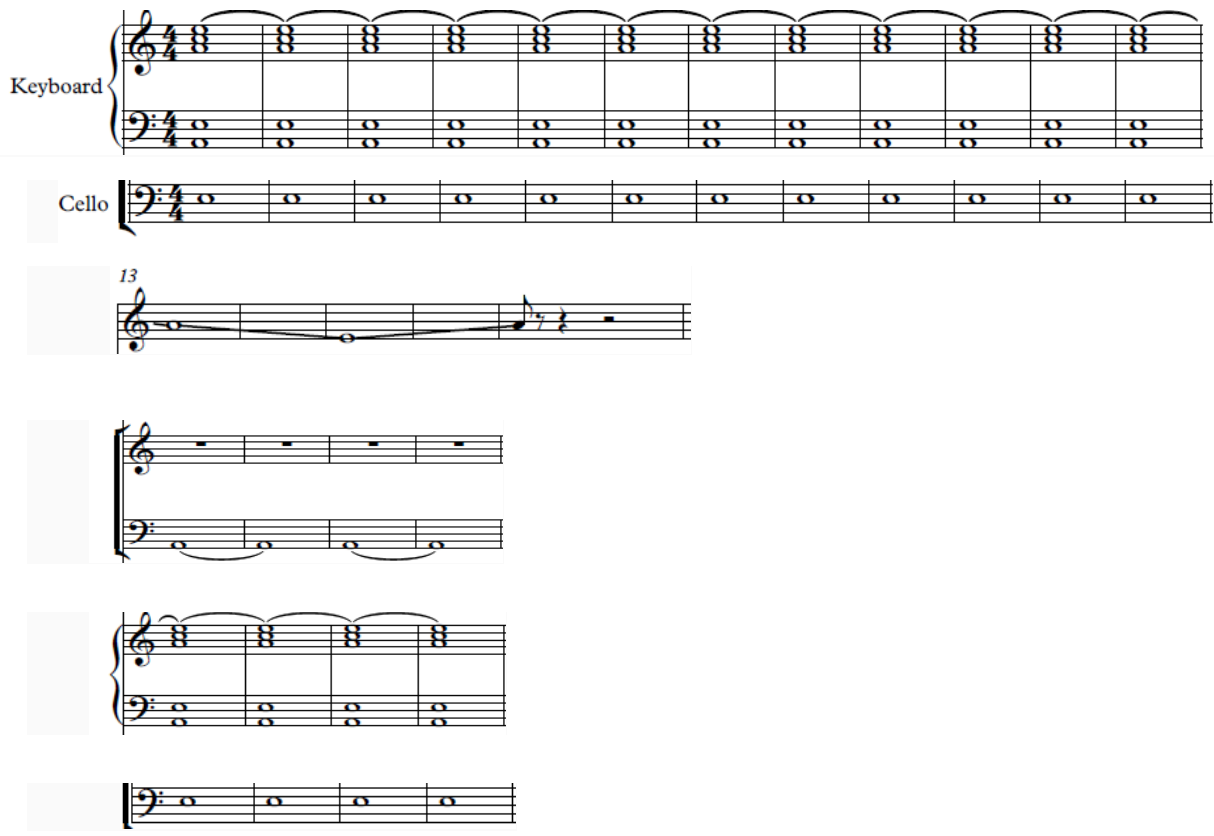

b. Kemewahan

Kemewahan Nabi Ayyub AS ditandai dengan masuknya instrumen rebana dengan tempo cepat (allegro) yang disambut dengan masuknya instrumen violin yang memainkan tehnik arpeggio sebagai latar dari tema melodi. Instrumen yang memegang tema melodi ialah xhylophone dengan notasi sebagai berikut.

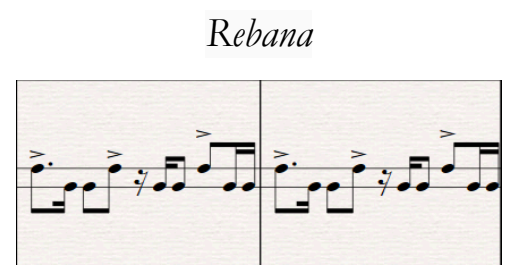

Keterangan warna suara rebana:

Garis bawah (tung)

Garis atas (tak)

Violin

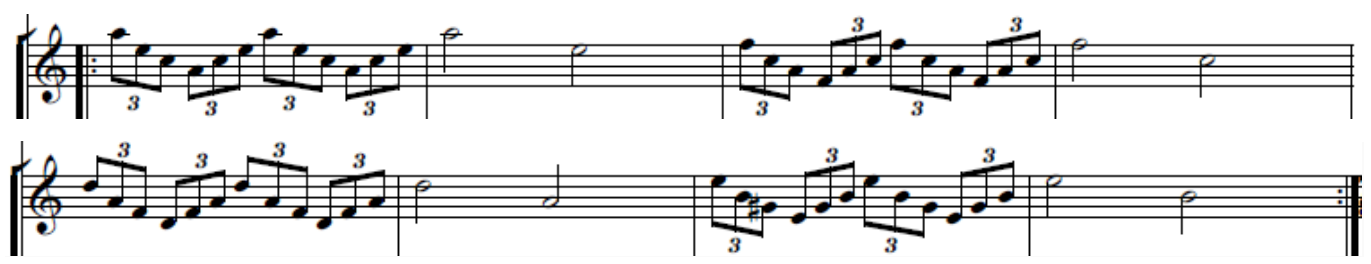




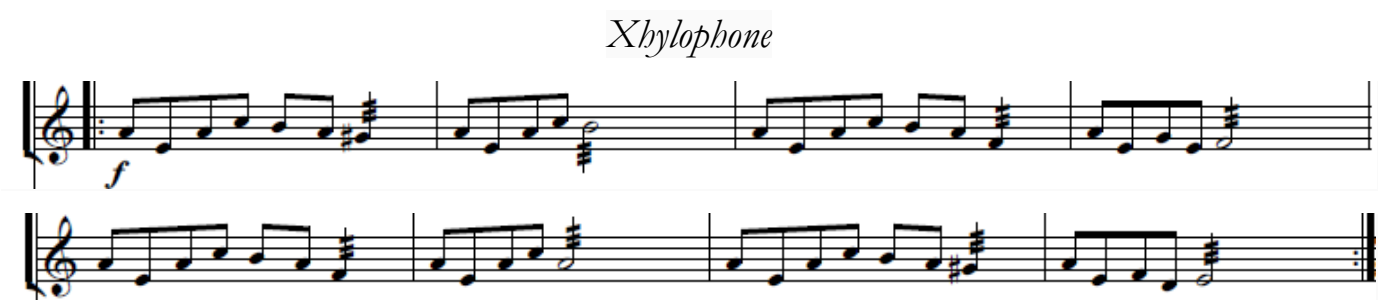

Ritme dari melodi yang dimainkan oleh xhylophone merupakan pola tabuhan rebana Gorontalo, di mana harga nadanya diperkecil (diminusi) dari $1 / 4$ ketuk menjadi $1 / 8$ ketuk. Pola tabuhan ini biasa disebut pola 5 dan 7. Setelah memainkan tema di atas, sukat berganti menjadi $7 / 8$ yang bermain sebanyak ritmis pada sukat $3 / 4$ tersebut
8 birama. Pemilihan sukat $7 / 8$ didapat dari unsur 7 pada pola tabuhan rebana Gorontalo. Unsur 3 dan 5 pada pola tabuhan rebana Gorontalo juga digunakan setelah sukat 7/8 berakhir. Unsur 3 digunakan menjadi sukat $3 / 4$, sedangkan unsur 5 menjadi batas jumlah

\section{Pola 7}

Pola 5

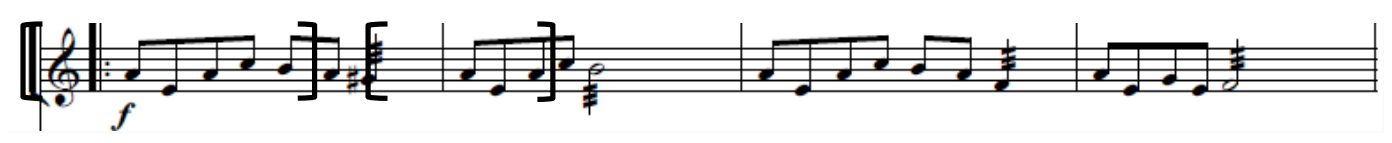

Unsur 7

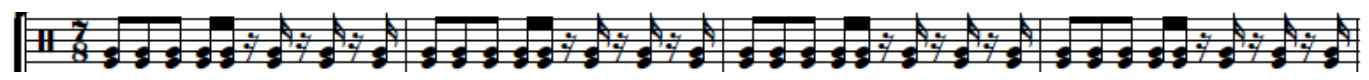

Unsur 3
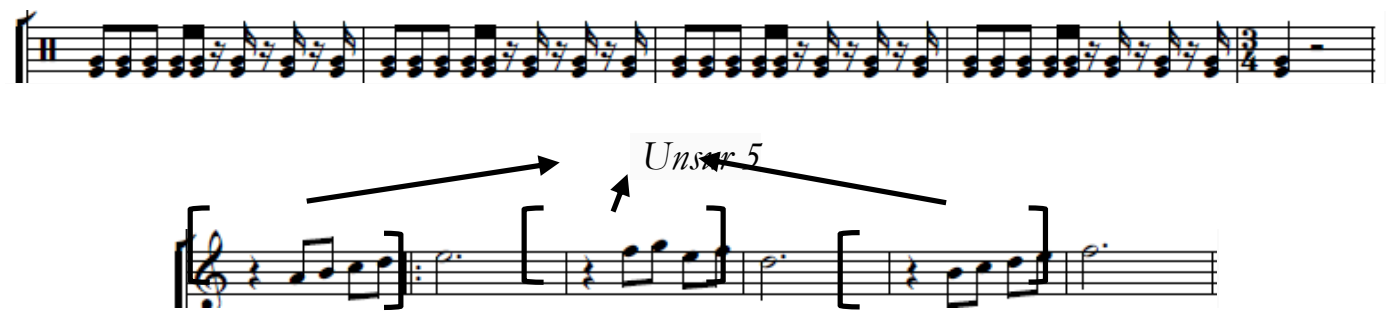
2. Bagian II

Bagian ini menggambarkan Instrumen gambus oud memainkan tema kehidupan Nabi Ayyub AS dan istrinya. melodi yang sama seperti xhylophone Bagian II ini ditandai oleh instrumen (unison). Permainan unison diinterpretasikan xhylophone yang memainkan kalimat melodi sebanyak 4 birama dan diulang pada tingkat nada ke 4 (modulasi). Kenaikan tingkat nada ini dimaksudkan untuk menambah ketegangan pada suasana yang dibangun. Setelah itu nada dasar dikembalikan lagi seperti semula ditambah masuknya sebagai penyakit yang menyerang tubuh Nabi Ayyub AS yang semakin lama semakin banyak. Akhir dari bagian II ini ditandai dengan melodi akhir yang disebut dengan drikir yang diiringi oleh instrumen bass elektrik yang bermain satu nada sebagai instrumen violin, dan gambus oud.
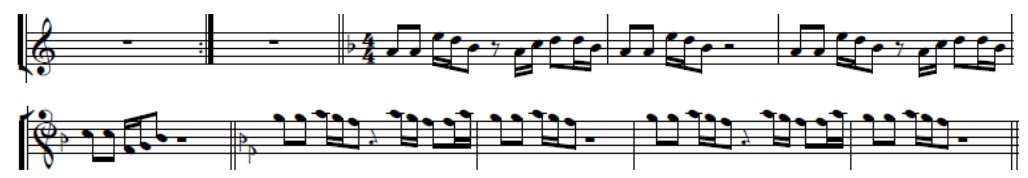

Ond

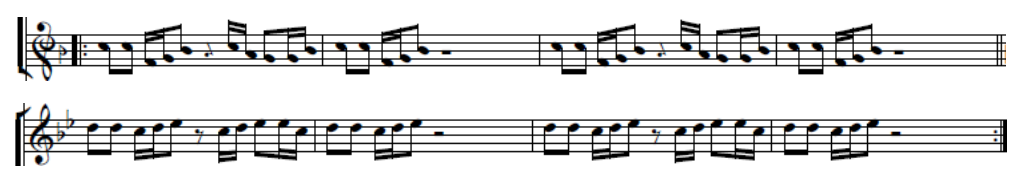

Drikir dengan 3 pembagian suara dan 3 pembagian ritmis

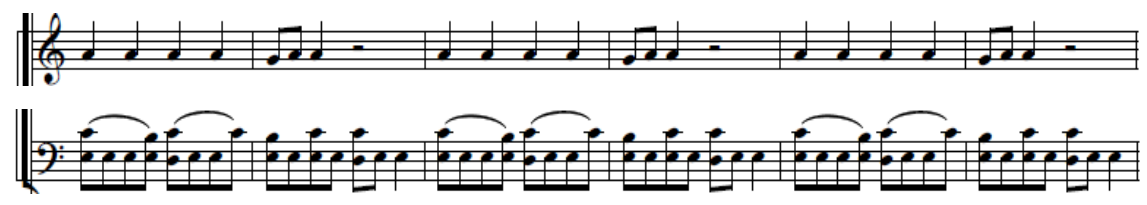

Bagian ini menggambarkan ketabahan

3. Bagian III (Nabi Ayyub sembuh dari penyakitnya)

Nabi Ayyub AS setelah sekian lama menghadapi musibah yang menimpa diri 
beliau. Akhirnya beliau diberikan kesembuhan dan diberkahi oleh Allah SWT.

Pada bagian ini violin dan oud berperan sebagai isian pada melodi utama yang dinyanyikan oleh vocalis dalam sukat 4/4. Ketabahan Nabi Ayyub AS terhadap musibah yang dideritanya kemudian direpresentasikan pada sebuah lirik yang berisi permohonan doa kepada Allah SWT agar disembuhkan dari penyakit dengan menggunakan dialeg Gorontalo. Berikut lirik dan notasinya.

Lagu yang dibawakan oleh vocalis ini memiliki dua bagian dengan panjang kalimat yang berbeda-beda. Berikut kalimat tanya dan jawab yang terletak pada setiap bagian.

Bagian I

(Kalimat tanya birama 1-7, Kalimat jawab birama 8-10)
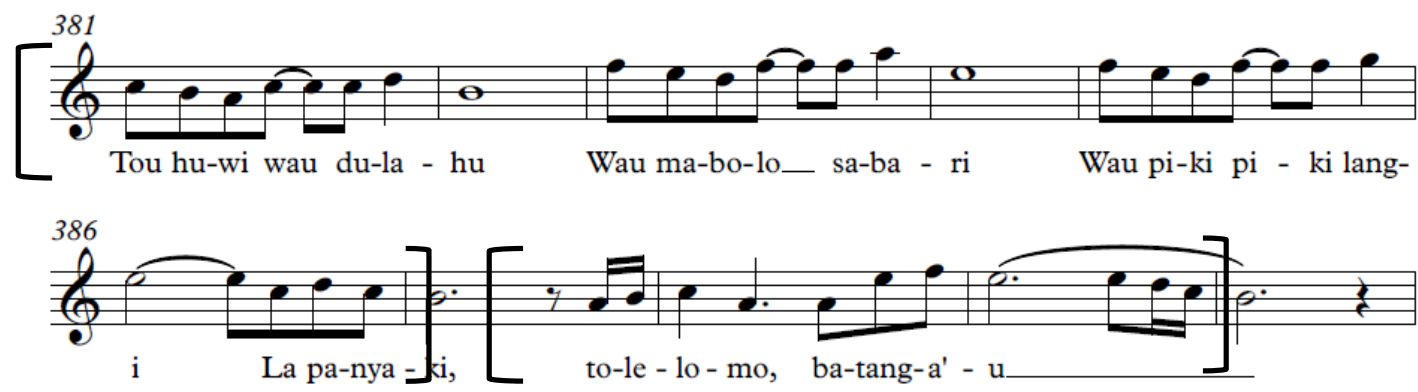

Bagian II

kalimat tanya

kalimat jawab
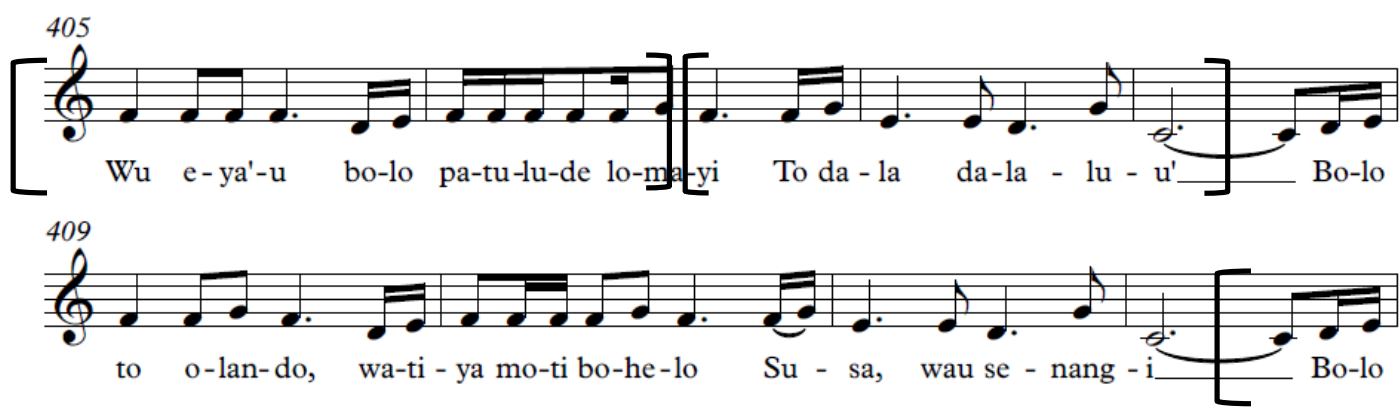

kalimat tanya

kalimat tanya

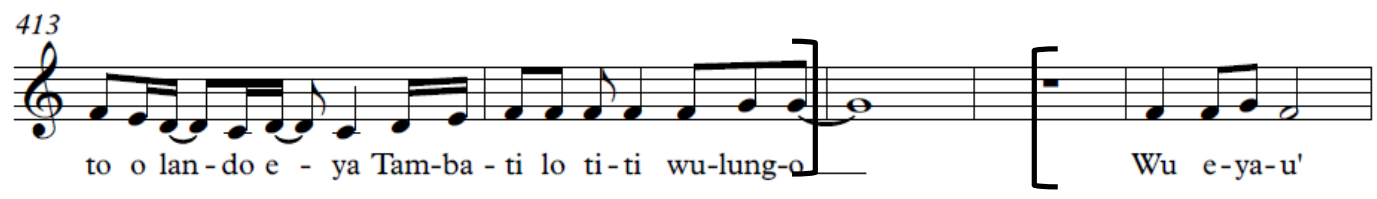

kalimat jawab 

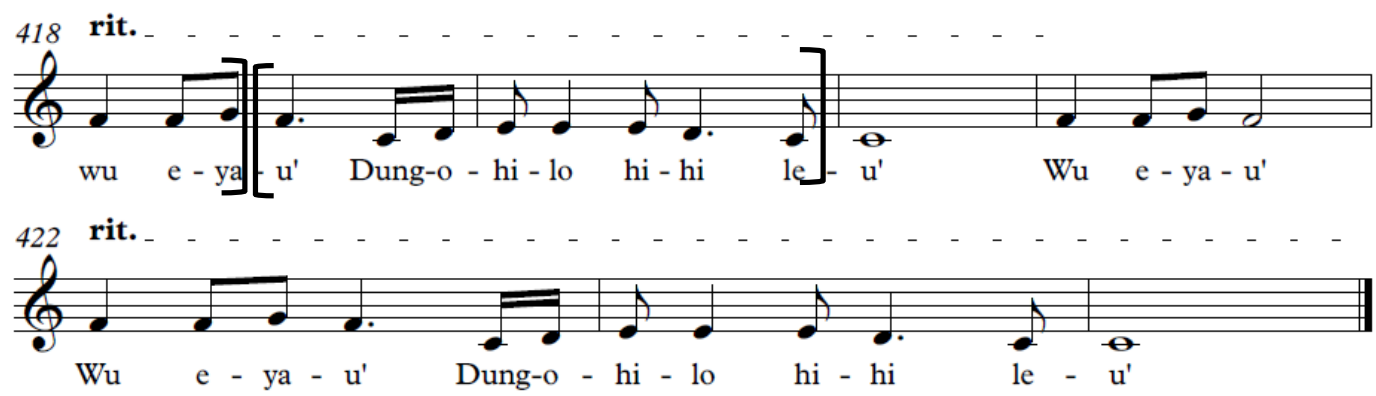

a. Lirik

Tou buwi wau dulabu

Wau mabolo sabari

Wau piki-piki langi

Lo panyaki todelomo batanga'u

Watiya tau oayibu

Moti bongohu motitiyopa

Bolo dua wau ibilasi

Mobile ambungu ob Eyau

Wu Eyau bolo potulude lomayi

To dala-dala lu'u

Boloto'olantho Eya watiya motibonelo

Susa wau sanangi

Boloto'olantho Eya

Tambati lo titi wulungo

Wи Eуau wu Eyau

Dungobilo bibi'leu

Wu Eyau wu Eyan

Dungobilo bibi'leu
Di dalam siang dan malamku

Aku dalam kesabarnku

Dan aku berpikir

Dalam penyakit yang aku derita selama ini

Aku yang bergelimang dosa

Tempatku bersujud

Hanya doa yang ikhlas kupanjatkan

Memohon pengampunan atas dosaku Ya

Allah

Ya Allah berikan aku petunjuk

Ke jalan Yang benar

Hanya kepadamu aku bersandar

Susah dan senang

Dan hanya kepadamu

Tempatku berserah diri dari cobaan

Ya Allah Ya Allah

Dengarkanlah doa doa ku ini

Ya Allah Ya Allah

Dengarkanlah doa doa ku ini 


\section{Simpulan}

Musik etnis Mo'ela merupakan suatu bentuk karya musik etnis yang lahir dari tradisi lisan masyarakat Gorontalo yaitu turunani. Kisah hidup Nabi Ayyub AS yang terdapat dalam sastra lisan dan pola rebana yang monoton menjadikan rangsangan untuk pembuatan karya ini dan dibuat menjadi dinamis dan bervariatif dengan penggunakan alat instrumen musik yang digunakan. Penggunaan instrumen barat juga mendukung karya ini. Karya Mo'ela disajikan secara vokal instrumental, karya ini merupakan perpaduan antara beberapa instrumen barat dengan instrumen timur yang di dalamya ada beberapa isntrumen musik khas dari Gorontalo.

Teori yang digunakan dalam karya ini adalah teori Alma M. Hawkins, dengan metode penciptaan eksplorasi, improvisasi, dan komposisi. Penciptaan karya ini juga dipadukan berdasarkan pengalaman maupun teori atau cara-cara yang didapat selama menempuh pendidikan. Karya musik Mo'ela dibagi mejadi tiga bagian yaitu, bagian awal (I), bagian tengah (II), bagian akhir (III) yang setiap bagian menceritakan kisah hidup nabi Ayyub AS.

\section{E. Daftar Pustaka}

Banoe, Pono. 2003. Kamus Musik. Yogyakarta: Penerbit KANISIUS.

Bay, Suwardi. 2010. "Alat Musik Tradisional Daerah Gorontalo", (Makalah Dinas Pendidikan Nasional Kota Gorontalo). Sebagai bahan ajaran mata pelajaran Muatan Lokal di Provinsi Gorontalo.

Danesi, Marcel. 2012. Pesan, Tanda dan Makna, terj. Evi Setyarini dan Luci Lian Piantari. Yogyakarta: Jalasutra.

Daulima, Farha. 2007. Mengenal Sastra Lisan Daerah Gorontalo. Gorontalo: Forum Suara Perempuan LSM Mbu’i Bungale.

Eaton, Marcia Muelder. 2010. PersoalanPersoalan Dasar Estetika. Jakarta: Salemba Humanika.

Ellfeldt, Lois. 1977. A Primer For Choreographers. Terj. Sal Murgiyanto dengan judul Pedoman Dasar Penata Tari. Jakarta: Lembaga Pengembangan Kesenian Jakarta.

Fungsi Alat Musike Tradisional Gambus, http:// fungsialat.blogspot.co.id/2015/ 10/ fungsi-alat-musik-tradisionalgambus.html, akses pada 29 Desember 2019.

Hadi, Sumandiyo. 2014. Koreografi BentukTeknik-Isi. Yogyakarta: Cipta Media.

2006. Seni dalam Ritual Agama. Yogyakarta: Pustaka.

Hawkins, Alma M. 1990. Creating Through Dance. Terj.Y.Sumandiyo Hadi dengan 
judul Mencipta Lewat Tari. Yogyakarta: Institut Seni Indonesia Yogyakarta.

https://nugrapilongo.wordpress.com/2008 /09/25/polopalo/, akses pada 20 Januari 2020, pukul 03.35 WIB.

http://simfonik.id/instrumen string.html, akses pada tanggal 29 Desember 2019 pukul 14.02 WIB.

https://www.djarumcoklat.com/article/alat -musik-flute-untuk-orkestra, akses pada 29 Desember 2019 pukul 14.08 WIB.

Husain, Yamin. 2011. "Turunani Dendang Kenduri Masyarakat Gorontalo". Gorontalo: Karya Tulis (Diajukan sebagai Profesi Persyaratan Profesi Pamong Belajar SKB Limboto Kabupaten Gorontalo).

Mack, Dieter. 2009. Sejarah Musik Jilid 4. Yogyakarta: Pusat Musik Liturgi.

Martono, Hendro. 2015. Panggung Pertunjukan dan Berkesenian. Yogyakarta: Cipta Media.

Mc Dermott, Vincent. 2013. Imagination: Merubah Musik Biasa Menjadi Luar Biasa. Terj. Nhata H.P. Dwi Putra. Yogyakarta: Art Musik Today.

Moleong, Lexy J. 2017. Metodologi Penelitian Kualitatif. Bandung: PT Remaja Rosdakarya.

Muhammad Fauzi Mukolil. 2015. "Turunani dalam Adat Molapi Saronde Pada Upacara Pernikahan di Provinsi Gorontalo". Skripsi untuk mencapai derajat Strata 1 pada Program Studi
Etnomusikologi, Fakultas Seni Pertunjukan, Institut Seni Indonesia Yogyakarta.

Monoarfa, Rangga. Musik turunani sebagai sumber inspirasi Penciptaan musik etnis dengan judul mo'ela. Skripsi S1 Program Studi Etnomusikologi Fakultas Seni Pertunjukan Institut Seni Indonesia Yogyakarta. 2020.

Nuraini, Indah. 2011. Tata Rias dan Busana Wayang Orang Gaya Surakarta. Yogyakarta: Badan Penelitian ISI Yogyakarta.

Prier SJ, Karl-Edmund. 1996. Ilmu Bentuke Musik. Yogyakarta: Pusat Musik Liturgi. . 2009. Kamus Musik. Yogyakarta: Pusat Musik Liturgi.

Smith, Jacqualine. 1985. Dance Composition Guide for Teacher. Terj. Ben Suharto dengan judul Komposisi Tari: Sebuah Petunjuk Praktis Bagi Guru. Yogyakarta: Ikalasti.

Tim Penyusun Pusat Bahasa. 2008. Kamus Besar Bahasa Indonesia. Jakarta: Pusat Bahasa Departemen Pendidikan Nasional.

Yusuf, Frengky. 2015. "Fungsi Turunani dalam Upacara Adat Hui Mopotilandahu di Desa Talulobutu Kecamatan Tapa kabupaten Bone Bolango Provinsi Gorontalo". Skripsi untuk mencapai derajat Strata 1 pada Program Studi Sendratasik, Fakultas Sastra dan Budaya, Universitas Negeri Gorontalo. 
